\title{
EFFECT ON FEMORAL A-V GLUCOSE DIFFERENCE OF INSULIN INJECTED INTO AN ANTECUBITAL VEIN AND INTO A FEMORAL ARTERY ${ }^{1}$
}

\author{
By DAVID M. BELL AND THOMAS BURNS
}

(From the Department of Medicine, School of Medicine, Duke University, Durham, N. C.)

(Submitted for publication December 31, 1951; accepted May 12, 1952)

There still exists considerable controversy with respect to the importance of the liver as compared to the peripheral tissues (skeletal muscle) in the homeostasis of blood sugar levels. The place and mechanism of action of insulin remain unclear.

Mann and Magath (1) are credited with first establishing the peripheral action of insulin apart from the liver. This was done in evisceration experiments in dogs. Frank, Nothmann and Wagner $(2,3)$, working with rabbits and pancreatectomized dogs, claimed a local peripheral action of insulin following its injection into a femoral artery. In vitro, it has been shown that the glucose uptake of the rat diaphragm is increased under the action of added insulin (4-6). Stadie and Zapp (7) have demonstrated that insulin is fixed to the diaphragm and cannot be washed off.

The purpose of this paper is to record data demonstrating the different effect on femoral $\mathrm{A}-\mathrm{V}$ glucose difference of insulin injected into a femoral artery and into an antecubital vein.

\section{METHODS}

Convalescent hospital patients and normal medical students served as subjects.

All studies were done in the morning and the subjects had had no food for 12 to 14 hours. They were at rest for an hour prior to insulin injection. No attempt was made to control room temperature.

The main femoral artery and vein were used for sampling. Samples were drawn simultaneously into heparinized syringes and immediately transferred to tubes prepared by the evaporation of $1 \mathrm{ml}$. of 3 percent sodium fluoride and these were then placed in ice. Using barium hydroxide and zinc sulfate precipitation, filtrates were made at the completion of the experiment.

Crystalline Zinc Insulin (Squibb and Lilly), freshly diluted in saline for each experiment, was used. In all cases, the dose was $1 / 80$ unit per kilogram. The time of

1 This investigation was supported in part by a research grant from the Life Insurance Medical Research Fund and in part by a research grant from the National Institutes of Health, U. S. Public Health Service. injection was one-half minute or less, unless otherwise stated.

The blood sugar concentrations were determined on 2 $\mathrm{ml}$. of whole blood by the Iodometric Titration method of Somogyi $(8,9)$. In our hands this method provided a high degree of accuracy. The average standard deviation calculated from results obtained from replicate samples of whole blood was $\pm 0.47 \mathrm{mg}$. per $100 \mathrm{ml}$. A-V glucose differences of $2 \mathrm{mg}$. per $100 \mathrm{ml}$. or greater are significant. The resting arterial, venous and $A-V$ glucose concentration was found to be remarkably constant in a series of 22 subjects when checked over intervals of two to 25 minutes (10).

Blood oxygen concentration was determined by the method of Hickam and Frayser (11).

\section{RESULTS}

The first set of observations was made on hospital patients who were considered free from metabolic disorders and were well-nourished. They were divided into two groups of ten patients each. Insulin was injected intravenously into an antecubital vein in one group and intra-arterially into the right femoral artery in the remainder. In all cases, blood was obtained from the main fe-

TABLE I

Femoral arterio-venous blood sugar differences (mg. per $100 \mathrm{ml}$.)

Hospital patients receiving 1/80 unit insulin per kilogram into antecubital vein

\begin{tabular}{l|r|r|r|r|r|r}
\hline \multicolumn{1}{c|}{ Pt. } & Control & 5 min. & 15 min. & 30 min. & 45 min. & $60 \mathrm{~min}$. \\
\hline J. A. & 4.5 & 3.9 & 2.4 & 5.0 & 13.8 & \\
S. S. & 3.8 & 0.7 & -3.1 & 1.8 & 3.2 & \\
N. & -0.5 & -0.1 & -1.4 & 2.4 & & 10.9 \\
R. S. & -0.4 & 1.9 & 0.4 & 2.0 & & \\
J. & 3.7 & 1.2 & 0.1 & 4.2 & & 9.0 \\
W. S. & 6.2 & -0.7 & -1.5 & & & \\
R. & 5.5 & 3.7 & 0.1 & 6.8 & 4.7 & \\
J. J. & 5.5 & -2.1 & 3.7 & 4.3 & & \\
M. P. & 2.6 & 1.1 & -3.1 & 2.5 & -0.6 & 0.6 \\
M. P. & 3.2 & -1.5 & 0.1 & 2.3 & & 3.1 \\
MEAN & 3.4 & 0.8 & -0.23 & 3.4 & 5.2 & 5.7 \\
& & p $<0.01$ & $\mathrm{p}<0.01$ & & & \\
\hline
\end{tabular}

$\mathrm{p}$-refers to $\mathrm{A}-\mathrm{V}$ differences at the times listed, compared to control values. 
TABLE II

Femoral arterio-venous blood sugar differences (mg. per $100 \mathrm{ml}$.)

Hospital patients receiving 1/80 unit insulin per kilogram into right femoral artery

\begin{tabular}{l|r|r|r|r|r|r}
\hline \hline Pt. & Control & 5 min. & 15 min. & 30 min. & 45 min. & $60 \mathrm{~min}$. \\
\hline W. T. & 1.0 & 2.7 & 1.0 & 5.0 & 5.8 & 4.2 \\
N. B. & 0.7 & 2.0 & 3.8 & 2.8 & 1.1 & 3.3 \\
L. W. & 1.7 & 7.4 & 5.1 & 5.6 & 9.2 & \\
J. N. & -0.9 & 4.9 & 1.8 & 14.8 & 19.5 & 15.8 \\
B. & -0.5 & 0.6 & 4.0 & 6.9 & & 6.9 \\
S. & 0.9 & & & 14.8 & & 18.6 \\
E. L. & 4.3 & 3.7 & 4.0 & 7.4 & 4.1 & \\
M. S. & 0.6 & 6.8 & 2.7 & 5.7 & & 6.7 \\
B. & 6.0 & 6.4 & & 6.6 \\
C. & & -0.6 & 2.3 & & & 5.2 \\
MEAN & 1.5 & 3.4 & 3.4 & 7.8 & 7.9 & 8.6 \\
& & $p<0.2$ & $p<0.1$ & $p<0.01$ & $p<0.05$ & \\
\hline
\end{tabular}

p-refers to A-V differences at the times listed, compared to control values.

moral artery and vein of the right leg. Table I presents the A-V sugar differences at various times after the intravenous injection of insulin. During the period of fall in arterial sugar there was not a measurable $\mathrm{A}-\mathrm{V}$ difference, but following the 15-minute period when the arterial concentration was rising, a measurable $\mathrm{A}-\mathrm{V}$ glucose difference returned. Table II presents the data on the second group of hospital patients in whom the insulin was injected intra-arterially. The A-V sugar differences are statistically wider at 15 and 30 minutes than those after intravenous injection $(p=0.01$ and $p<0.01)$. Figures 1 and 2 are composite curves constructed from the average value in milligrams percent at each time interval.

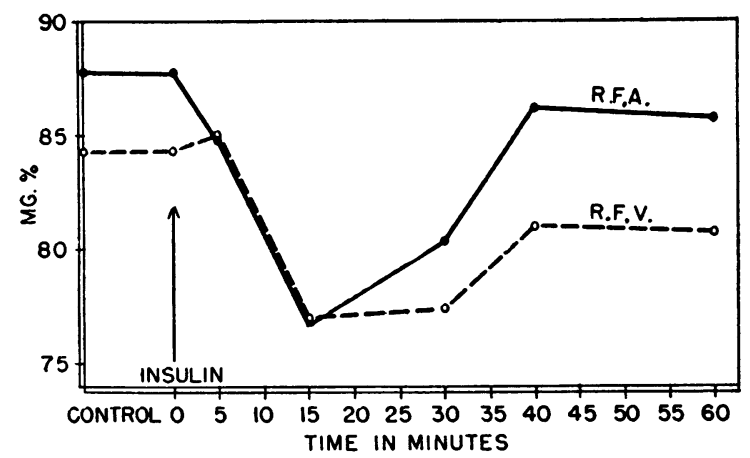

Fig. 1. Composite Graph: Ten Patients Who ReCEIVEd Intravenous Insulin (1/80 Unit PER KiloGRAM)

R.F.A.-Glucose concentration in right femoral artery R.F.V.-Glucose concentration in right femoral vein

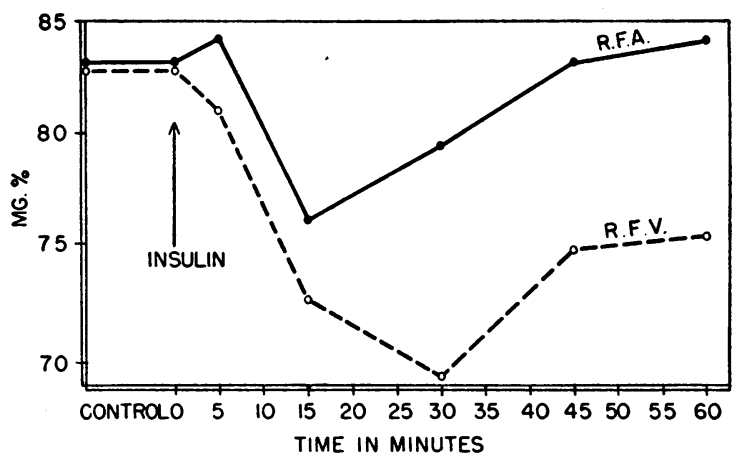

Fig. 2. Composite Graph: Ten Patients Who ReCEIved Intra-ARTERIAL INSUlin ( $1 / 80$ Unit PER KiloGRAM)

R.F.A.-Glucose concentration in right femoral artery R.F.V.-Glucose concentration in right femoral vein

The second set of observations was made on seven normal male students. Insulin was injected intra-arterially into the right femoral artery, and venous blood was obtained from the main femoral veins of both legs. Table III and Figure 3 present the $\mathrm{A}-\mathrm{V}$ differences in blood sugar as found in this group. It should be noted that the last two subjects in Table III (K. G. and B. N.) received insulin given over a five-minute period. During

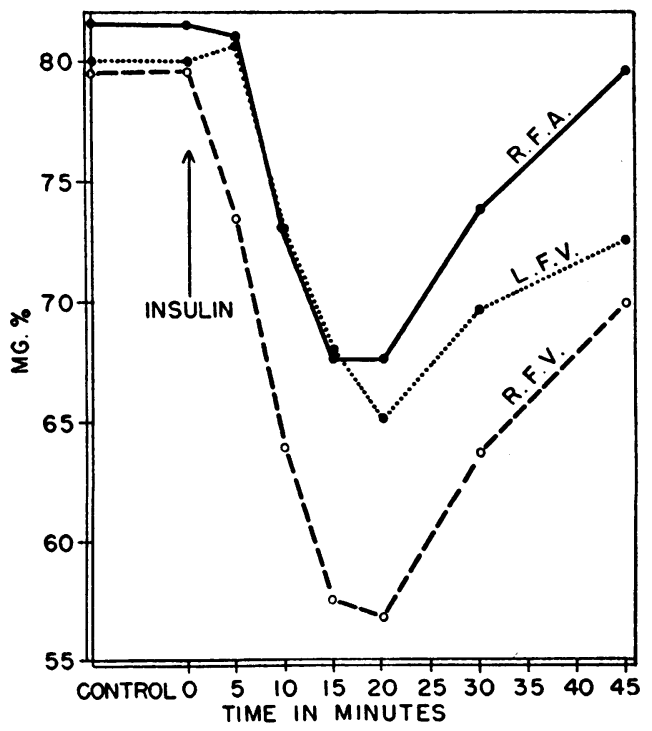

Fig. 3. Composite Graph : Seven Normal Students Who Received Intra-ARTERIAL Insulin (1/80 UNIT PER KILOGRAM)

R.F.A.-Glucose concentration in right femoral artery R.F.V.-Glucose concentration in right femoral vein L.F.V.-Glucose concentration in left femoral vein 
TABLE III

Femoral arterio-venous blood sugar differences (mg. per $100 \mathrm{ml}$.) in normal students receiving 1/80 unit insulin per kilogram into right femoral artery

\begin{tabular}{|c|c|c|c|c|c|c|c|c|c|c|c|c|c|c|}
\hline \multirow{2}{*}{ Subj. } & \multicolumn{2}{|c|}{ Control } & \multicolumn{2}{|c|}{$5 \mathrm{~min}}$. & \multicolumn{2}{|c|}{$10 \mathrm{~min}}$. & \multicolumn{2}{|c|}{$15 \mathrm{~min}}$. & \multicolumn{2}{|c|}{$20 \mathrm{~min}}$. & \multicolumn{2}{|c|}{$30 \mathrm{~min}}$. & \multicolumn{2}{|c|}{$45 \mathrm{~min}}$. \\
\hline & RFV & LFV & RFV & LFV & RFV & LFV & RFV & LFV & RFV & LFV & RFV & LFV & RFV & LFV \\
\hline $\begin{array}{l}\text { D. B. } \\
\text { J. W. } \\
\text { K. W. } \\
\text { J. H. } \\
\text { S. V. } \\
\text { K. G. } \\
\text { B. N. }\end{array}$ & $\begin{array}{l}1.6 \\
0 \\
1.7 \\
2.6 \\
3.6 \\
1.4 \\
3.9\end{array}$ & $\begin{array}{r}1.2 \\
-1.8 \\
1.1 \\
1.2 \\
2.0 \\
1.9 \\
4.1\end{array}$ & $\begin{array}{r}2.9 \\
12.2 \\
8.4\end{array}$ & $\begin{array}{r}2.7 \\
-0.8 \\
-2.7\end{array}$ & $\begin{array}{r}4.0 \\
9.6 \\
16.4 \\
6.5\end{array}$ & $\begin{array}{r}0.4 \\
1.1 \\
-0.9 \\
-0.5\end{array}$ & $\begin{array}{r}4.4 \\
12.5 \\
3.0 \\
8.2 \\
18.2 \\
11.3\end{array}$ & $\begin{array}{c}-8.1 \\
-5.7 \\
3.6 \\
0 \\
0 \\
1.2 \\
6.1\end{array}$ & $\begin{array}{r}13.8 \\
4.5 \\
12.6 \\
8.1 \\
9.2 \\
19.4 \\
8.0\end{array}$ & $\begin{array}{r}2.3 \\
-2.3 \\
3.9 \\
5.4 \\
3.9 \\
3.3 \\
0.8\end{array}$ & $\begin{array}{r}10.7 \\
9.0 \\
4.9 \\
5.6 \\
11.0 \\
18.8 \\
10.1\end{array}$ & $\begin{array}{r}-2.8 \\
7.6 \\
1.6 \\
3.8 \\
6.6 \\
7.3 \\
4.8\end{array}$ & $\begin{array}{r}16.0 \\
8.5 \\
4.2\end{array}$ & $\begin{array}{r}14.4 \\
4.9 \\
1.7\end{array}$ \\
\hline MEAN & 2.1 & 1.4 & $\begin{array}{r}7.6 \\
\mathbf{p} \\
\mathbf{p}^{\prime}\end{array}$ & $\begin{array}{l}0.4 \\
01\end{array}$ & $\begin{array}{r}9.1 \\
\mathbf{p} \\
\mathbf{p}^{\prime}\end{array}$ & $\begin{array}{l}0.02 \\
.02 \\
.01\end{array}$ & $\begin{array}{c}9.6 \\
\mathbf{p} \\
\mathbf{p}^{\prime}\end{array}$ & $\begin{array}{l}-0.4 \\
.01 \\
.01\end{array}$ & $\begin{aligned} 10.8 & \\
\mathbf{p} & < \\
\mathbf{p}^{\prime} & <\end{aligned}$ & $01^{2.5}$ & $\begin{array}{r}10.0 \\
\mathbf{p} \\
\mathbf{p}^{\prime}\end{array}$ & $.05^{4.1}$ & 9.6 & 7.0 \\
\hline
\end{tabular}

RFV-Arterio-venous difference in right femoral artery and right femoral vein.

LFV-Arterio-venous difference in right femoral artery and left femoral vein.

p-Comparing RFV and LFV at each time.

$\mathrm{p}^{\prime}$-Comparing RFV at each time with control RFV.

the fall in arterial glucose concentration, all subjects had a greater $\mathrm{A}-\mathrm{V}$ sugar difference across the leg into which the insulin was directed. In the opposite leg, the A-V glucose difference disappeared during the period of fall in arterial glucose concentration.

Table IV presents the oxygen values obtained on the student group. The exact time of sampling varied from subject to subject and the time grouping in this table is approximate. These data show no consistent trend and are presented to show that the observed changes in A-V sugar differences in the injected leg were not caused by a striking reduction in blood flow. This is based on the as-

TABLE IV

Femoral arterio-venous blood oxygen differences (Vol. percent)

Normal student group-insulin in right femoral artery

\begin{tabular}{|c|c|c|c|c|c|c|c|c|}
\hline & \multicolumn{2}{|c|}{ Control } & \multicolumn{2}{|c|}{$15 \mathrm{~min}}$. & \multicolumn{2}{|c|}{$22 \mathrm{~min}}$. & \multicolumn{2}{|c|}{$40 \mathrm{~min}}$. \\
\hline & RFV & LFV & RFV & LFV & RFV & LFV & RFV & LFV \\
\hline $\begin{array}{l}\text { D. B. } \\
\text { J. W. } \\
\text { K. W. } \\
\text { J. H. } \\
\text { S. V. } \\
\text { K. G. } \\
\text { B. N. }\end{array}$ & $\begin{array}{l}3.5 \\
3.3 \\
3.9 \\
6.6 \\
3.9\end{array}$ & $\begin{array}{l}3.1 \\
4.7 \\
6.7 \\
5.2\end{array}$ & 9.5 & 8.8 & $\begin{array}{l}2.9 \\
1.9 \\
3.0 \\
4.8 \\
6.4 \\
4.8\end{array}$ & $\begin{array}{l}4.4 \\
3.1 \\
5.4 \\
6.6 \\
6.5\end{array}$ & $\begin{array}{l}5.3 \\
\\
4.0 \\
3.6 \\
4.8 \\
7.3 \\
4.8\end{array}$ & $\begin{array}{l}3.6 \\
3.4 \\
5.5 \\
7.3 \\
6.2\end{array}$ \\
\hline MEAN & 4.2 & 4.9 & 8.4 & 8.8 & 4.0 & 5.2 & 5.0 & 5.2 \\
\hline
\end{tabular}

RFV-Arterio-venous difference right femoral artery and right femoral vein.

LFV-Arterio-venous difference right femoral artery and left femoral vein. sumption that the increased removal of sugar after insulin does not cause a major change in oxygen uptake (4-6), and therefore the A-V oxygen difference can be used to determine directional changes in blood flow.

\section{DISCUSSION}

Study of the sites of action of insulin in the body is complicated by the fact that any large change in the blood sugar sets in motion a series of homeostatic reactions. The problem is simplified by using a dose of insulin just large enough to cause a definite but small lowering of the arterial blood sugar level.

The intravenous injection of $1 / 80$ unit of insulin in the hospital patients caused an average fall of $11 \mathrm{mg}$. per $100 \mathrm{ml}$. in the arterial blood sugar level. From inspection of the arterial and femoral venous curves, we cannot tell in what tissue the sugar disappears. The disappearance of the preinjection A-V glucose difference across the leg suggests that in this dose the insulin decreases the rate of removal of sugar by the leg. We do not believe that this means that insulin is interfering with glucose removal, but that the apparent decrease in rate of glucose removal is probably secondary to the fall in the arterial glucose level and probably does not represent a direct effect of insulin on the tissues of the extremity.

In the group of hospital patients receiving insulin intra-arterially, the A-V glucose difference 
widened as the arterial blood sugar level fell. The increased $\mathrm{A}-\mathrm{V}$ glucose difference is significant at 15 and 30 minutes when compared with the slightly negative $\mathrm{A}-\mathrm{V}$ differences of the intravenous injection.

In the students, the $\mathrm{A}-\mathrm{V}$ glucose difference widened significantly in the injected leg as the arterial blood sugar level fell. In these healthy students, the action of insulin was greater than in the hospital patients. The wide $A-V$ glucose difference in the injected extremity indicated increased removal of glucose as compared to the opposite extremity. In the non-injected extremity the $\mathrm{A}-\mathrm{V}$ glucose difference disappeared. Again, this is interpreted as the effect of lowering of arterial glucose concentration.

These data indicate that a large portion of the insulin injected into a femoral artery was active in the extremity and that it increased the glucose removal from blood perfusing that extremity without a corresponding increase in the opposite extremity. During the first 15 minutes, one has the opportunity to observe the effect of a marked increase in insulin activity in one extremity at a time when the complicating effects of the homeostatic mechanisms for restoring the arterial blood sugar level are reduced to a minimum. The concentration of the insulin in the extremity after intra-arterial injection is much greater than after giving the same amount in the antecubital vein. The data presented do not allow us to say whether or not the insulin is fixed in the leg in the same way that it is fixed to the rat's diaphragm.

While the data after intra-arterial injection demonstrate a local peripheral effect of insulin on the rate of glucose removal, the data from the intravenous injection suggest that there are areas in the body that are more sensitive to the action of insulin than the lower extremities.

\section{SUMMARY}

1. The injection of $1 / 80$ unit of insulin per kilogram into an antecubital vein caused a decrease in the femoral A-V glucose difference.
2. The injection of $1 / 80$ unit of insulin per kilogram into the right femoral artery caused an increase in the $\mathrm{A}-\mathrm{V}$ glucose difference in the injected extremity and a decrease in the opposite extremity.

3. The data indicate that the removal of glucose in the leg can be increased by the action of insulin; but when insulin is given intravenously in doses of $1 / 80$ unit per kilogram, the lowering of the arterial sugar is caused by the action of insulin on other tissues more sensitive to it than the lower extremity.

\section{REFERENCES}

1. Mann, F. C., and Magath, T. B., Studies on the physiology of the liver. VII. Effect of insulin on blood sugar following total and partial removal of the liver. Am. J. Physiol., 1923, 65, 403.

2. Frank, E., Nothmann, M., and Wagner, A., Extrahepatische wirkung des insulins beim zuckerverbraugh. Klin. Wchnschr., 1924, 3, 581.

3. Frank, E., Nothmann, M., and Wagner, A., Ueber den angriffspunkt des insulins. Archiv. f. exper. Path. u. Pharmakol., 1925, 110, 225.

4. Gemmill, C. L., Effect of insulin on the glycogen content of isolated muscles. Bull. Johns Hopkins Hosp., 1940, 66, 232.

5. Krahl, M. E., and Cori, C. F., Uptake of glucose by the isolated diaphragm of normal, diabetic and adrenalectomized rats. J. Biol. Chem., 1947, 170, 607.

6. Stadie, W. C., and Zapp, J. A., Jr., Effect of insulin upon the synthesis of glycogen by the rat diaphragm in vitro. J. Biol. Chem., 1947, 170, 55.

7. Stadie, W. C., Haugaard, N., Marsh, J. B., and Hills, A. J., Chemical combination of insulin with muscle (diaphragm) of normal rat. Am. J. M. Sc., 1949, 218, 265.

8. Somogyi, M., A new reagent for the determination of sugars. J. Biol. Chem., 1945, 160, 61.

9. Somogyi, M., Determination of blood sugar. J. Biol. Chem., 1945, 160, 69.

10. Bell, D. M., Femoral arterio-venous differences in fasting humans. Submitted for publication.

11. Hickam, J. B., and Frayser, R., Spectrophotometric determination of blood oxygen. J. Biol. Chem., 1949, 180, 457. 